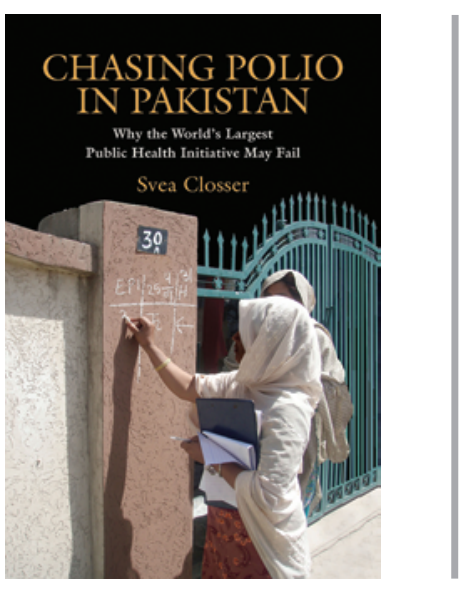

\title{
Chasing polio in Pakistan
}

\section{Why the world's largest public health initiative may fail}

\author{
Svea Closser \\ Vanderbilt University Press. Nashville, Tennessee, USA. 2010. \\ 256 pp. \$59.95. ISBN: 978-0-826-51708-1 (hardcover).
}

Reviewed by Samuel L. Katz

Department Of Pediatrics, Duke University, Durham, North Carolina, USA.

E-mail: katz0004@mc.duke.edu

\section{I}

In Chasing Polio in Pakistan: Why the World's Largest Public Health Initiative May Fail, Svea Closser, a Middlebury College assistant professor of anthropology, has written a thoughtful and provocative assessment of the Polio Eradication Initiative (PEI) based on her own field work in 2006-2007. Closser, married to a Pakistani man and fluent in Urdu, had access to field workers and government officials, and provides greater insight than might be expected from a Western author. As an anthropologist, Closser strove to evaluate the progress and deficits of the program from a political and societal perspective rather than a technical or operational one. The result is a very convincing evaluation of the causes of failures to date, and Closser extrapolates that the lessons learned in fighting polio in Pakistan might apply to problems in other nations and to eradication efforts for diseases such as measles and malaria.

Pakistan is one of the four countries (along with Nigeria, India, and Afghanistan) in which polio has remained endemic since the World Health Assembly voted in 1988 to eradicate the disease by the year 2000. Ten years after that target date, Nigeria and India show promise of possibly attaining eradication in the next several years, whereas Pakistan and Afghanistan lag. Although the two nations have some similar problems, Pakistan's are unique in several respects. Immense floods in the summer of 2010 ravaged the Swat valley, resulting in the displacement and migration of several millions of people, the absence of running water and electricity, the destruction of housing, the loss of crops and food supply, and the closure of at least 500 health clinics and facilities. Although these tragic developments transpired three years after Closser's experiences and the preparation of her manuscript, much of what she portrays and professes is relevant in assessing the likelihood of success or failure of global eradication endeavors.

Closser believes that because polio has been eradicated in the Americas and in most of Europe, Pakistani government leaders view this global program as a goal of the affluent nations imposed on them by WHO and the United Nations. To them, the priority of the disease pales in comparison to so many other national problems of much higher magnitude. Although they pay lip service to the PEI, there is marked foot dragging and false compliance in Islamabad's call on district and province officials to implement vaccination efforts. Health initiatives in general are at the bottom of the national government's agenda, and the burden of polio is perceived as minor relative to that of diarrheal disease, respiratory infections, and meningitis. The national government's influence is unpredictable in a nation in which central government has variable success in effecting local action. As Closser points out, "District employees resisted the directives of their superiors in a number of ways, including refusal to work, falsification, corruption, false compliance, and direct confrontation." Nevertheless, Closser notes that the mothers of infants and children "accepted polio vaccination without giving the matter much thought." More than 40 international consultants were in Pakistan during Closser's field work, each costing WHO about $\$ 10,000$ per month for secured housing and chauffeured land cruisers. Meanwhile, the local vaccinators were paid $\$ 2.00$ per day for a five-day week, traveling on foot through their assigned districts; supervisors might have a bicycle or, rarely, a motorcycle for transportation.

These are but a few of the observations and conclusions that Closser clearly details in her pages. She argues that societal and political considerations, not virologic or immunologic factors, are preventing eradication. Rather than a top-down approach (i.e., Geneva to Islamabad to district offices), she advises collaborative operations in which diverse non-governmental organizations can work on site with local agencies in an amicable advisory capacity on a district-bydistrict basis (the WHO is not authorized to operate below the national offices in Islamabad). She suggests that partnership should replace authoritarian directives.

The detailed operational information Closser has gathered and described so vividly cannot be found in PEI reports or scientific reviews. Hers is a revelation of problems that erode the daily implementation of the eradication initiative in Pakistan. In her conclusion, Closser states that "awareness of power relationships and resistance as well as formal planning for institutional flexibility would, I believe, better position eradication programs to reach their goals. Taking these steps might shift the balance from the possible toward the probable." Those responsible for overall direction of the PEI would do well to read and consider her presentation. This reviewer, who has lengthy experience at the CDC and WHO levels, is persuaded that her refreshing anthropological approach may provide solutions to the persistent challenges that have postponed for more than a decade the attainment of global eradication of polio. 